\title{
Intussuscepção de Intestino Delgado em Paciente Adulto por Gist: Relato de Caso e Revisão da Literatura
}

\author{
Small Intestine Intussusception in Adult Due to GIST: A Case Report
}

\author{
FLÁVIABALSAMO ${ }^{1}$; BÁRBARA HELOISAZANCHETTA POZZOBON²; JULIANA SUAREZ WOLF²; \\ SÉRGIO HENRIQUECOUTO HORTA ${ }^{1}$; GALDINO JOSÉ SITONIOFORMIGA ${ }^{3}$
}

\author{
1. Assistentes do Serviço de Coloproctologia do Hospital Heliópolis- São Paulo, SP, TSBCP; ${ }^{2 .}$ Residentes do Serviço de \\ Coloproctologia do Hospital Heliópolis, SP; ${ }^{3 .}$ Chefe do Serviço de Coloproctologia do Hospital Heliópolis, SP, TSBCP.
}

\begin{abstract}
BALSAMO F; POZZOBON BHZ; WOLF JS; HORTA SHC; FORMIGA GJS. Intussuscepção de Intestino Delgado em Paciente Adulto por Gist: Relato de Caso e Revisão da Literatura. Rev bras Coloproct, 2009;29(2): 237-241.

RESUMO: A intussuscepção do intestino delgado em adultos é rara e geralmente está associada à presença de neoplasias. Dentre estas, o GIST, a neoplasia mesenquimal em 30\% dos casos é considerada de alto grau de malignidade, são ainda menos comuns. A intussuscepção relacionada ao GIST tem sintomatologia inespecífica e pode manifestar-se com obstrução, massa palpável no abdômen, hemorragia ou perfuração intestinal. Relata-se caso de intussuscepção intestinal em paciente adulto por GIST, com ênfase em seu diagnóstico e tratamento.
\end{abstract}

Descritores: Intussuscepção; Obstrução intestinal; Abdome agudo; Neoplasias abdominais; Metastático.

\section{INTRODUÇÃO}

A intussuscepção intestinal, embora muito comum em crianças, é uma doença rara em adultos, correspondendo a apenas $1 \%$ dos casos de obstruções intestinais. ${ }^{1,2}$

Geralmente tem etiologia bem definida em 80 a $90 \%$ dos casos e as neoplasias são as principais causas na maioria das séries. ${ }^{1,2}$

Embora o intestino delgado corresponda a aproximadamente $75 \%$ do trato gastrointestinal, é sede de menos de $25 \%$ de todas as neoplasias gastrointestinais. ${ }^{3,4}$

Os tumores do intestino delgado, raramente vistos na prática clínica, são,em sua maioria, benignos. ${ }^{5}$ No entanto, alguns tipos histopatológicos malignos podem ocorrer, como adenocarcinomas, tumores carcinóides, tumores estromais, linfomas, tumores endócrinos e metástases. ${ }^{3}$
O tumor estromal gastrointestinal (GIST) é considerado atualmente a neoplasia mesenquimal mais comum do trato gastrointestinal. ${ }^{6}$ Entre 10 a $30 \%$ dessas neoplasias são consideradas de alto grau de malignidade, tendo como possíveis sítios metastáticos o fígado e a cavidade peritoneal. ${ }^{6}$ Tem origem em células progenitoras das células intersticiais de Cajal (steam cell), que são consideradas como o marca-passo celular do tubo digestivo, gerando seu movimento pendular. ${ }^{6-8}$ Semelhante a estas, expressam o receptor transmembrana da tirosina-kinase CD 117 (proteína KIT) e CD34 e mutações com ativação destes receptores, proporcionadas pelo proto-oncogene KIT , desenvolvem a neoplasia. ${ }^{7,8}$

Há vinte anos eram considerados como originários de músculo liso, sendo atualmente sua origem estabelecida no mesênquima do trato gastrointestinal. ${ }^{7,8}$ $\mathrm{O}$ aumento crescente de casos novos nos últimos anos está relacionado ao progresso das técnicas 
diagnósticas. ${ }^{7,8}$ Apesar de tais recursos, são de difícil diagnóstico e geralmente estão clinicamente avançados no momento de seu tratamento definitivo. ${ }^{3}$ Podem causar dor abdominal insidiosa e perda de peso, ou criar emergências cirúrgicas como hemorragia, perfuração e obstrução. ${ }^{3}$

O objetivo deste estudo é relatar um caso de intussuscepção de intestino delgado em adulto causado por GIST e fazer revisão da literatura.

\section{RELATO DO CASO}

E.C.S., 47 anos, sexo masculino, branco, natural de Recife, PE e procedente de São Paulo, SP. Há três meses apresenta alteração do hábito intestinal ( uma evacuação a cada três dias), associada à dor abdominal, em queimação, no mesogástrio, com períodos de acalmia; vômitos pós prandiais precoces, de conteúdo alimentar e emagrecimento de $25 \mathrm{~kg}$. Apresenta antecedente de síndrome do pânico, em tratamento com clonazepan $2 \mathrm{mg} / \mathrm{dia}$ e cloridrato de clomipramina $10 \mathrm{mg} / \mathrm{dia}$; e tabagista (um maço/dia) por 20 anos.

Ao exame físico com regular estado geral, descorado 3+/4+, hidratado e afebril. Nota-se o abdome pouco distendido, timpânico, flácido, com massa abdominal de limites mal definidos em mesogástrio, móvel e medindo aproximadamente $10 \mathrm{~cm}$ de diâmetro, pouco dolorosa à palpação profunda. $\mathrm{O}$ exame proctológico evidenciou trombose hemorroidária externa, não sendo possível a continuidade do exame devido à dor. A tomografia de abdome e pelve demonstrou massa abdominal heterogênea de contornos bem definidos e imagem "em alvo", sugestiva de intussuscepção intestinal, sem evidencia de metástases hepáticas. (Figuras 1 e 2).

A radiografia de tórax identificou massa nodular única no lobo superior esquerdo, de aproximadamente $5 \mathrm{~cm}$ de diâmetro, confirmada por tomografia de tórax, sugestiva de lesão secundária. Foi realizada broncoscopia, que evidenciou compressão extrínseca de brônquio fonte esquerdo e realizada biópsias transbrônquicas. A Endoscopia digestiva alta até segunda porção duodenal, não revelou alterações.

Evoluiu com aumento da distensão abdominal e dor abdominal difusa, vômitos e taquicardia. Foi indicada laparotomia exploradora com hipótese diagnóstica de abdome agudo obstrutivo. No inventário da cavidade abdominal constatou-se pequena quanti-
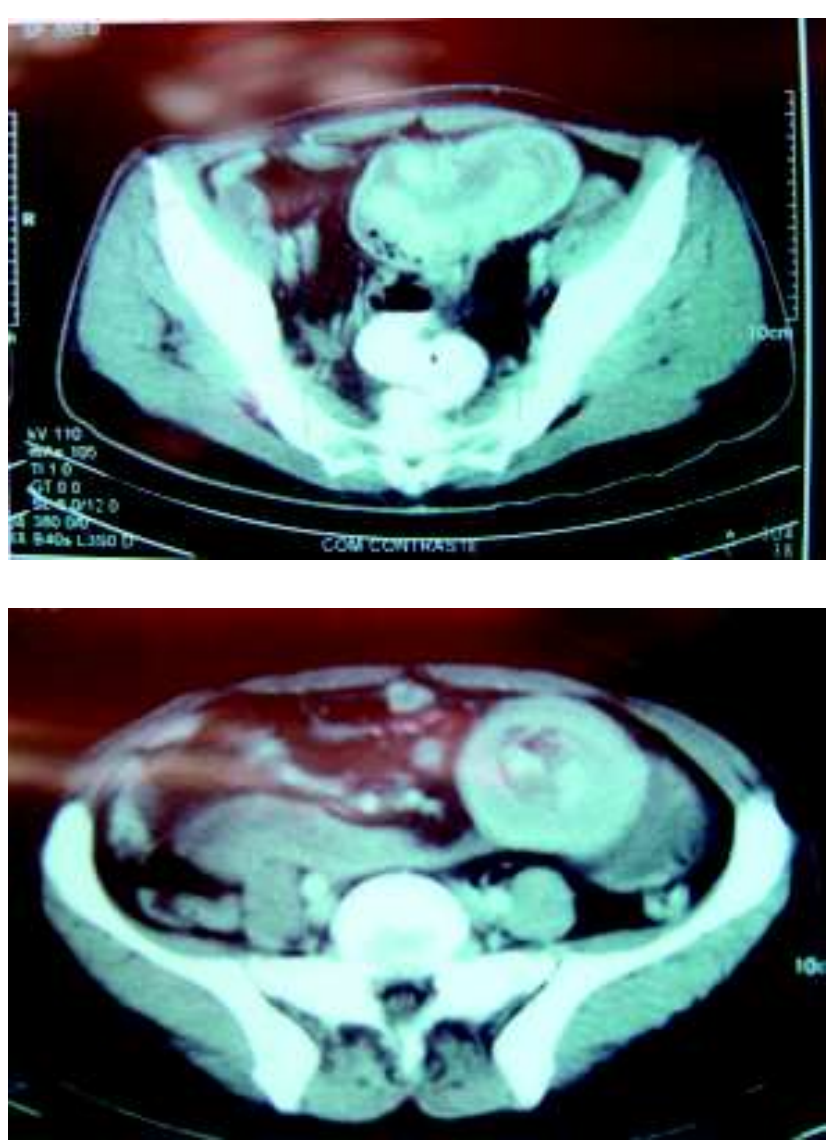

Figuras 1 e 2 - TC de abdome - massa abdominal heterogênea e circunscrita.

dade de ascite, pouco turva e, importante distensão de jejuno, a $50 \mathrm{~cm}$ do ângulo de Treitz, com intussuscepção jejuno-jejunal, não redutível, provocada por lesão tumoral intra-luminal. (Figuras 3 e 4).

Distalmente à área de intussuscepção foi identificada outra lesão tumoral, não obstrutiva, de aproximadamente $3 \mathrm{~cm}$ de diâmetro, e que apresentava rica vascularização na subserosa. (Figura 5).

O paciente foi submetido à enterectomia (30 $\mathrm{cm})$ compreendendo as duas lesões tumorais, coletando-se de líquido ascítico para cultura com antibiograma e lavagem da cavidade com solução fisiológica. A abertura da peça cirúrgica evidenciou lesões de aspecto esbranquiçado, irregular e exofíticas. (Figura 6).

O exame histopatológico identificou neoplasia indiferenciada, com intensa anaplasia e altos índices de mitoses. (Figura 7).

A imuno-histoquímica revelou c-kit positivo, confirmando o tumor estromal gastrointestinal (GIST). (Figura 8). 

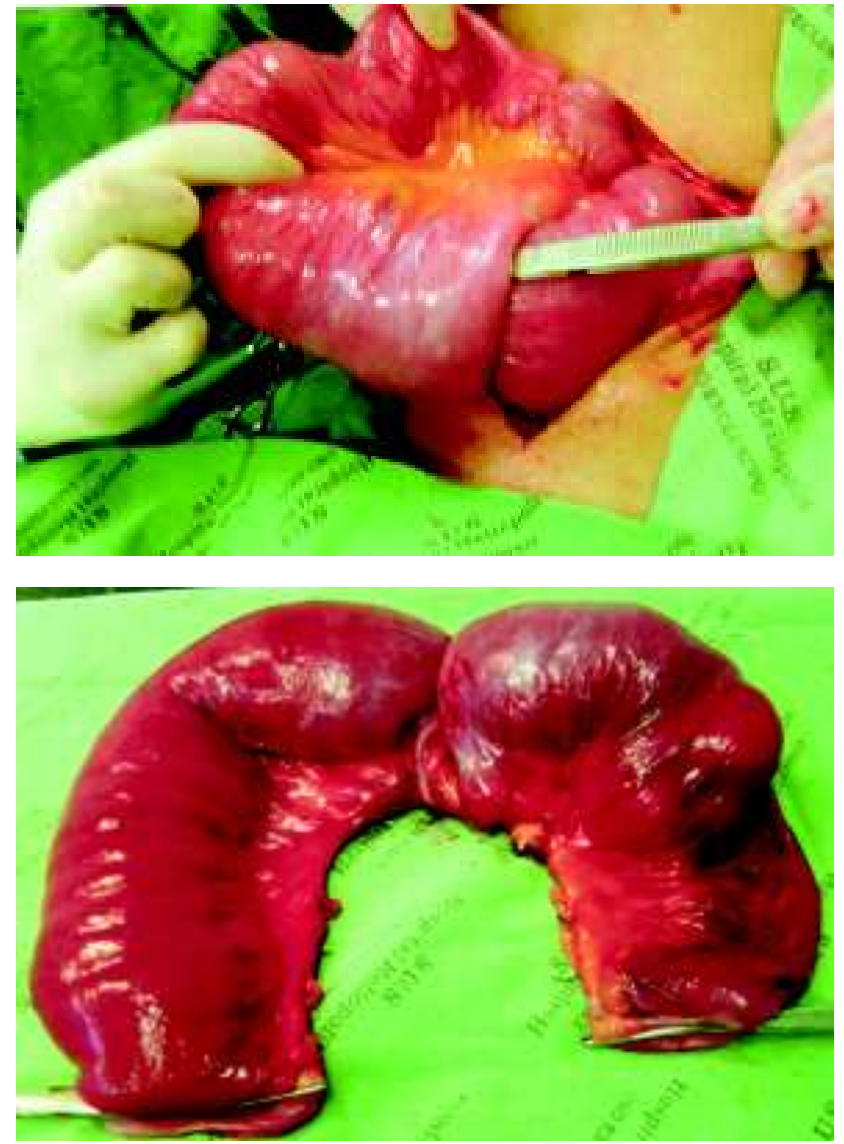

Figuras 3 e 4 - Intussuscepção jejuno-jejunal.

O exame histopatológico da lesão torácica demonstrou alterações semelhantes às da lesão intestinal.

$\mathrm{O}$ paciente manteve-se taquicárdico nos primeiros três dias de pós-operatório apesar da antibioticoterapia com cefalosporina de terceira geração e anaerobicida. Evoluiu com choque séptico no $4^{\circ}$ dia de pós-operatório necessitando ventilação mecâni-

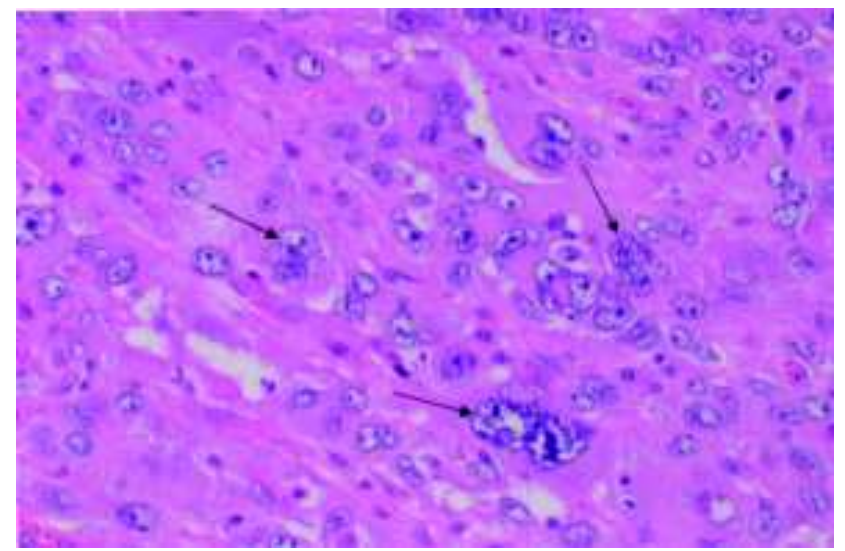

Figura 7 - HE (400x) neoplasia indiferenciada.

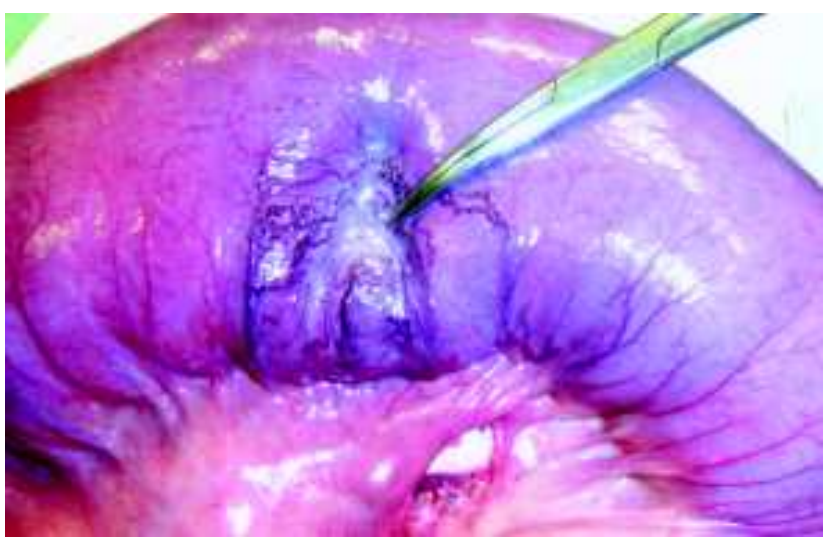

Figura 5 - Lesão distal à intussuscepção.

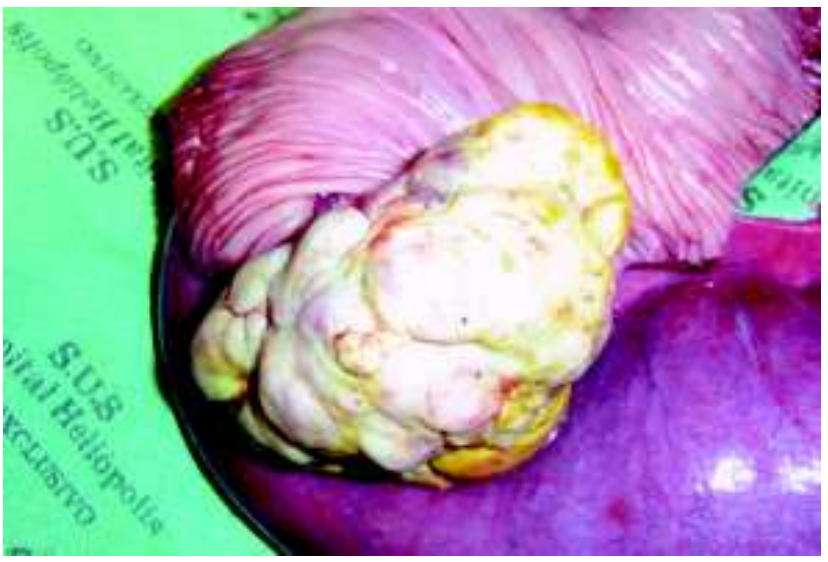

Figura 6 - Lesão tumoral de jejuno.

ca, drogas vasoativas, hemoculturas e cuidados de terapia intensiva. Realizada ultrassonografia abdominal que não evidenciou líquido livre na cavidade. Manteve-se em choque séptico não responsivo ao tratamento clínico, e no $7^{\circ}$ dia de pós operatório foi submetido à nova ultrassonografia que evidenciou líquido livre na cavidade abdominal. Devido à gravidade do quadro clí-

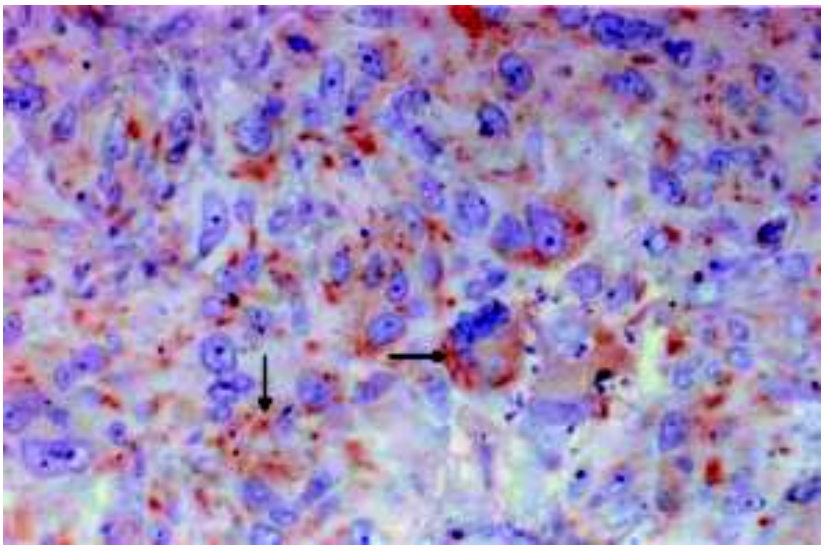

Figura 8 - c-KIT positivo (400x). 
nico e a impossibilidade de descartar complicações da anastomose, optou-se pela realização de laparotomia exploradora que evidenciou ascite citrina e anastomose jejuno-jejunal íntegra. A hemocultura foi positiva para candida albicans. Evoluiu com êxito letal no $8^{\circ}$ pósoperatório por choque séptico devido à fungemia refratária ao tratamento clínico.

\section{DISCUSSÃO}

A intussuscepção intestinal é rara em adultos e apresenta, na grande maioria das vezes, um fator etiológico associado. Os locais preferenciais de ocorrência são as junções dos segmentos livremente móveis com os retroperitoneais, ou fixos através de aderências. De acordo com a localização, pode-se classificar a intussuscepção intestinal em entérica, ileocólica, ileocecal e colo-cólica. ${ }^{1}$ No caso relatado a intussuscepção ocorreu em alça intestinal completamente solta e foi classificada como entérica jejuno-jejunal.

O mecanismo exato que precipita a intussuscepção ainda é desconhecido. A estimulação do intestino normalmente produz uma área de constrição à montante do estímulo e relaxamento a jusante. Acredita-se que qualquer lesão na parede intestinal ou irritante dentro do seu lúmen e que altere o padrão peristáltico normal, seja capaz de iniciar uma invaginação. $^{2}$

A associação do GIST com intussuscepção é muito rara $^{5}$ e a sintomatologia diferentemente da criança, é geralmente inespecífica e crônica, sugerindo obstrução intestinal ,na maioria das vezes. ${ }^{1}$

Tumores benignos e malignos do intestino delgado podem ocorrer em qualquer idade, com uma média de apresentação aos 50 anos, semelhante ao caso relatado. ${ }^{9}$

As manifestações clínicas inespecíficas ou associadas a outras doenças constituem obstáculos importantes ao diagnóstico e tratamento. ${ }^{9}$ Somente são suspeitados sob condições extremas como a presença de massa palpável, hemorragia gastrointestinal, perfuração ou obstrução. Outros sintomas relatados são: dor abdominal, náuseas, vômitos, diarreia, anemia crônica e perda de peso, ${ }^{5,9}$ o que também ocorreu como nosso paciente.

O diagnóstico inclui, história clínica e exame físico detalhados, e na vigência de queixas inespecíficas, deve-se investigar o intestino delgado, principalmente em casos de anemia ferropriva e sintomas obstrutivos. ${ }^{5}$ A tomografia computadorizada abdominal é o exame de escolha, tanto na identificação das tumorações abdominais quanto das metástases. ${ }^{5,10}$ Este fato também foi constatado no presente caso.

O tratamento de eleição é a ressecção completa e em bloco da lesão, sendo este fator importante na evolução. Margens alargadas não são necessárias, assim como não há necessidade de linfadenectomia rotineira. ${ }^{11}$ Devese ressecar sua pseudocápsula, se houver, e evitar o rompimento da lesão durante a dissecção ${ }^{6}$.

O GIST é caracterizado pela expressão imunohistoquímica do antígeno CD117, o que permite sua identificação, ${ }^{6}$ assim como demonstrado neste caso.

O prognóstico destas lesões depende do número de mitoses, tamanho, profundidade de invasão e presença ou não de metástases. ${ }^{8}$ Estas podem ocorrer em até $50 \%$ dos pacientes, mesmo naqueles submetidos a ressecções curativas. ${ }^{7}$ Embora as metástases mais comuns ocorram em peritôneo e fígado, eventualmente podem ocorrer em outros sítios à distância, como o pulmão. Neste caso foram constatadas lesões metastáticas hepáticas e pulmonares ainda no préoperatório, o que já determinava o diagnóstico tardio, com doença avançada no início do tratamento e prognóstico sombrio. A quimioterapia com Imatinib, um inibidor seletivo da proteína c-KIT mutada, está indicada no controle das metástases à distância. ${ }^{7}$

A suspeita clínica precoce em pacientes com sintomas inespecíficos de suboclusão intestinal, seguida de investigação detalhada com exames de imagem, é o caminho correto para o diagnóstico de quadros de intussuscepção intestinal, associada a tumorações do intestino delgado. Na presença do GIST, a completa ressecção cirúrgica constitui a melhor estratégia de tratamento, com possibilidade de cura da lesão.

\footnotetext{
ABSTRACT: Small intestinal intussusception in adults is rare and generally associated with neoplasms. Within them GIST, a mesenchymal neoplasm in which $30 \%$ of patients have high grade malignancy, are even less common. Intussusception and GIST may have unspecific symptoms and it almost always presents with obstruction, palpable abdominal mass, hemorrhage and bowel perforation. A case of intestinal intussusception in adult due to GIST is reported, emphasizing diagnose and treatment.
}

Key words: Intussusception; Intestinal obstruction; Acute abdomen; Abdominal neoplasms; Metastatic. 


\section{REFERÊNCIAS}

1. Lucena MT, Apel A, Silva MJM - Intussuscepção no adulto. Rev bras Coloproct, 2005;25(2):158-161.

2. Weilbaecher D, Bolin JA, Hearn D, Ogden W - Intussusception in adults. Review of 160 cases. Am J Surg 1971;121(5):531-5.

3. Catena F, Ansaloni L, Gazzotti F, Gagliardi S, Saverio SD, Cataldis AD, Taffurelli M-Small bowel tumours in emergency surgery: specificity of clinical presentation. ANZ J Surg 2005;75:997-999.

4. Adjepong SE, Parameswaram R, Perry A, Mathews R, Jones R, Butterworth, JR, Sigurdsson A - Gastroduodenal intussusception due to gastrointestinal stromal tumor (GIST) treated by laparoscopic Billroth II distal gastrectomy. Surg Laparoscopic Endosc Percutan Tech 2006; 16(4):245-247

5. Sunamak O, Karabicak I, Aydemir I, Aydogan F, Guler E, Cetinkaya S, Korman MU - An intraluminal leiomyoma of the small intestine causing invagination and obstruction. A case report. The Mount Sinai J of Med 2006;73(8):10791081.

6. Eisenberg L, Judson I-Surgery and Imatinib in the management of GIST: emerging approaches to adjuvant and neoadjuvant theray. Ann Surg Oncol 2004;11(5):465-475.

7. Nieto EA, Aufroy AL, Pórtulas ED, Cladera PR, Fernández RO, Martín AD et al - Gastrointestinal stromal tumors: experience in 49 patients. Clin Transl Oncol 2006;8(8):594-8.
8. Zivkovic V, Katic V, Nagorni A, Velickovic L, Milentijevic M, Dordevic B - Gastrointestinal stromal tumors (GISTs): definition, clinical, histological, immunohistochemical, and molecular genetic features, and predictors of malignant and differential diagnosis. Arch Oncol 2002,10(4):267-271.

9. Beltran MA, Cruces KS - Primary tumors of jejunum and ileum as a cause of intestinal obstruction: a case control study. Int J Surg 2007; 5(3):183-191.

10. Yalamarthi S, Smith RC-Adult intussusception: case reposts and review of literature. Postgrad Med J 2005;81:174-177.

11. DeMatteo RP, Lewis JJ, Leung D, Mudan SS, Woodruff JM, Brennan MF - Two hundred gastrointestinal stromal tumors: recurrence patterns and prognostic factors for survival. Ann Surg 2000;231(1):51-8.

\section{Endereço para correspondência:} FLÁVIA BALSAMO

Serviço de Coloproctologia do Hospital Heliópolis

R. Cônego Xavier, 276- Vila Heliópolis

04231-030- São Paulo, S.P.

T.: 11- 2274-7600 (ramal 244)

E-mail: flabal@uol.com.br 